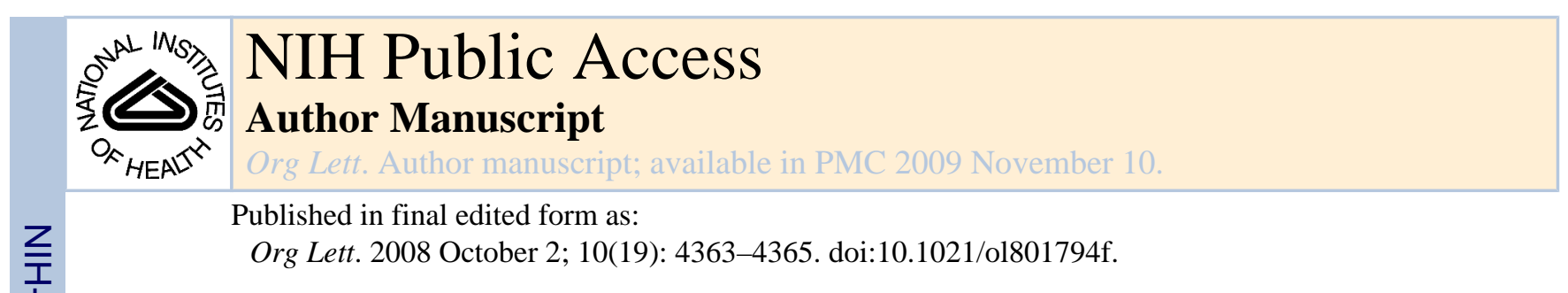

\title{
Total Synthesis of (-)-Aplaminal
}

Amos B. Smith III and Zhuqing Liu

Department of Chemistry, Laboratory for Research on the Structure of Matter, and Monell Chemical Senses Center, University of Pennsylvania, Philadelphia, Pennsylvania 19104

\section{Abstract}

Supporting Information Available: Experimental procedures and full spectroscopic data are available free of charge via the Internet at http://pubs.acs.org. 


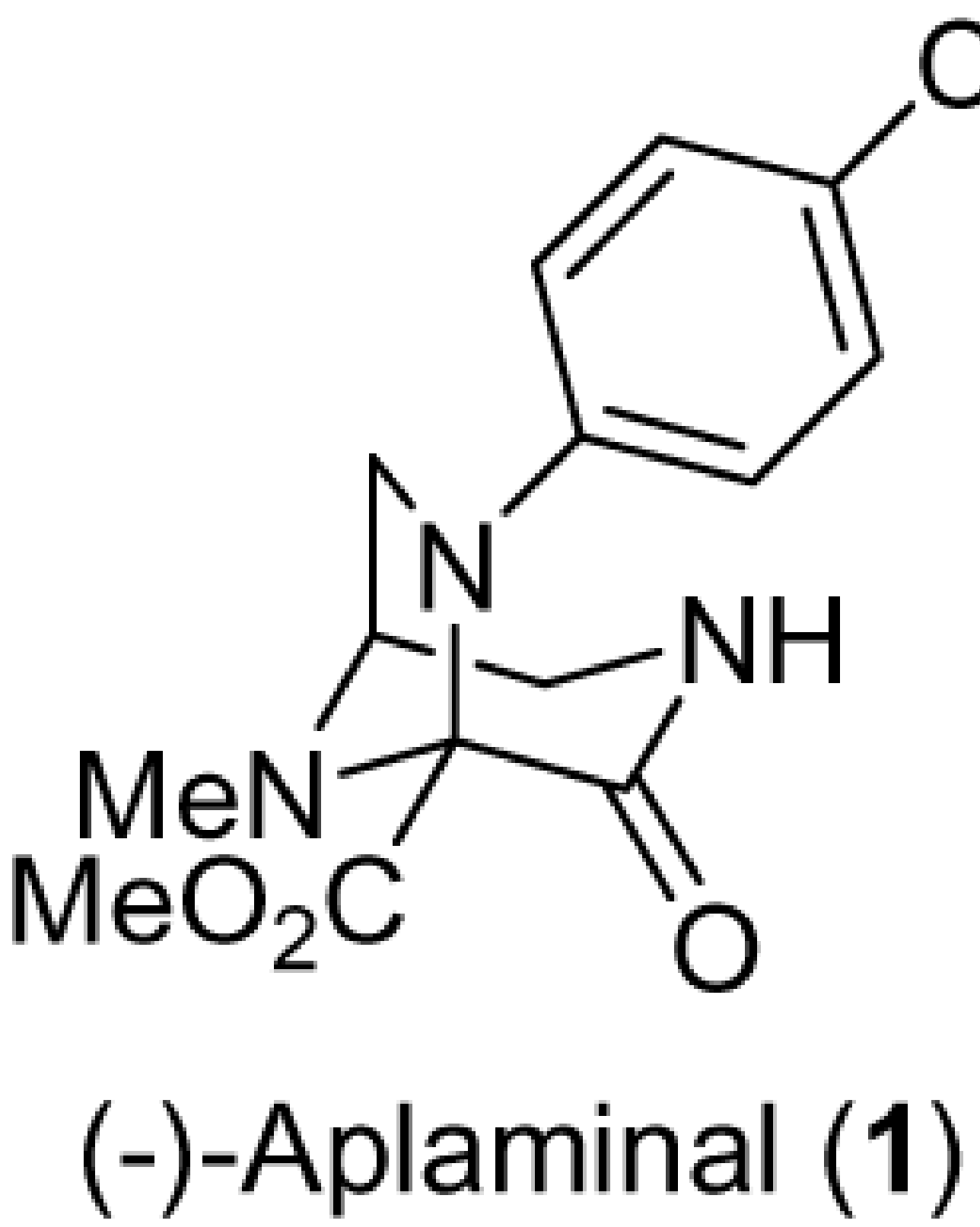

The total synthesis and assignment of absolute configuration of (-)-aplaminal (1), a cytotoxic metabolite from a sea hare possessing a triazobicyclo[3.2.1] octane skeleton, has been achieved. The synthesis entailed condensation of a monoprotected diamine (3) with dimethyl 2-oxomalonate (4) to generate the imidazolidine core (2). Introduction of the third nitrogen via Mitsunobu activation and azide displacement, followed by reduction and lactam formation $\left(\mathrm{AlMe}_{3}\right)$ furnished (-)-aplaminal (1). Overall, the synthesis entailed 9 steps and proceeded in $17 \%$ overall yield.

Aplaminal [(-)-1], isolated in 2008 by Kigoshi and coworkers ${ }^{1}$ from an extract of the sea hare Aplysia Kurodai, is endowed with a signature triazabicyclo[3.2.1] octane skeleton, each bridge possessing a nitrogen. The structure was initially assigned based on 1D and 2D NMR studies, in conjuction with HRMS, and then confirmed by X-ray crystallographic analysis. The absolute configuration was proposed based on a prospective biosynthetic proposal. Aplaminal [(-)-1] exhibits modest cytotoxicity against $\mathrm{HeLa} \mathrm{S}_{3}\left(\mathrm{IC}_{50}=0.51 \mu \mathrm{g} / \mathrm{mL}\right)$, albeit the mechanism of action is unknown. Taken together, the molecular structure and bioacitivity render (-)- 
aplaminal 1 a worthy target for chemical synthesis. Herein we report an effective total synthesis and assignment of the absolute configuration of (-)-aplaminal (1).

From the retrosynthetic perspective, disconnection of the six-membered ring amide in (-)-1 leads to the imidazolidine core 2 , which we envisoned could readily arise via condensation of an appropriately protected diamine $\mathbf{3}$ with dimethyl 2-oxomalonate $\mathbf{4} 2$ exploiting vicinal tricarbonyl chemistry. ${ }^{3}$ Diamine 3 in turn would be prepared from known (D)-serine methyl ester (-)-5, 4 assuming the assigned absolute configuration of (-)-1.

Towards this end, reduction of (-)-5 with DIBAL-H provided (D)-serinal ${ }^{5}$ (Scheme 2), which without isolation was treated with methyl 4-aminobenzoate to furnish diamine (-)-3 upon treatment with $\mathrm{NaBH}_{3} \mathrm{CN}^{6}$ in $72 \%$ yield. The imidazolidine core was next generated by removal of the Boc group with TFA, followed by the addition of dimethyl 2-oxomalonate 4; a beautiful crystaline solid $\left[(+)-\mathbf{6} ; \mathrm{mp} 94-95^{\circ} \mathrm{C}\right]$ resulted in $70 \%$ yield. The structure of $(+)-6$ was confirmed by single crystal X-ray analysis.

With (+)-6 in hand, we next sought to install the third amino group via an azide displacement after removal of the benzyl group and activation of the C(3) primary hydroxyl (aplaminal numbering). Removal of the benzyl group initially proved problematic. Either no reaction or decomposition was observed under hydrogenolysis using $\mathrm{Pd} / \mathrm{C}$ as catalyst in $\mathrm{MeOH}$ or EtOAc, either at room or elevated temperatures. Addition of acetic acid led to no improvement. Use of palladium hydroxide on carbon on the other hand led to over reduction at the $\mathrm{C} 1$ quartenary carbon to furnish (-)-7 (Scheme 3), as revealed by NMR ( ${ }^{1} \mathrm{H}$ and $13 \mathrm{C}$ ) and HRMS. The structure of (-)-7 was subsequently confirmed by 1D and 2D NMR. Surprisingly, allowing $(-)-7$ to stand over the course of 2 days in the presence of palladium hydroxide led to (+)-2, albeit in low yield.

Unaware at the time of the oxidation of (-)-7 to (+)-2, we turned to protection of the hydroxyl in (D)-serine as the tert-butyldiphenylsilyl (TBDPS) ether, anticipating facile removal via flouride ion at a late stage. In similar fashion to the first sequence, commercially available $\mathrm{N}$ Boc-(D)-serine [(-)-8] (Scheme 4) was converted to the corresponding methyl ester, followed by protection with TBDPSCl to provide ester (-)-9. Reduction with DIBAL-H to the corresponding serinal, ${ }^{7}$ followed by reductive-amination ${ }^{5}$ furnished diamine (-)-10. which upon removal of the Boc group and condensation with dimethyl 2-oxomalonate $\mathbf{4}$ readily provided the imidazolidine core (+)-11 in high yield (ca. 80\%). At this stage, the TBDPS group was easily removed with $\mathrm{TBAF} / \mathrm{HOAc}$ and the azide group introduced by employing Mitsunobu activation and displacement ${ }^{8}$ to furnish (+)-12. Methylation of the secondary amine with methyl trifluoromethanesulfonate, followed by hydrogenation $\left(\mathrm{Pd}(\mathrm{OH})_{2} / \mathrm{C}\right.$; EtOAc) furnished amine (+)-14, setting the stage for final ring closure. Pleasingly, treatment with $\mathrm{AlMe}_{3}$ in toluene completed the synthesis of (-)-aplaminal 1 in $66 \%$ yield as a crystalline solid. The physical and spectral properties $\left({ }^{1} \mathrm{H}, 13 \mathrm{C}\right.$ NMR) for synthetic (-)-aplaminal were in complete agreement with the data reported for the natural product, including melting point and chiroptical properties [synthetic: $\mathrm{mp} 233-235^{\circ} \mathrm{C} ;[\alpha]^{\mathrm{D}}-132(c 0.04$ in $\mathrm{MeOH})$; natural 1: $\mathrm{mp}$ $235-237^{\circ} \mathrm{C} ;[\alpha]^{\mathrm{D}}-133(c 0.02$ in $\left.\mathrm{MeOH})\right]$. The absolute configuration of (-)-aplaminal 1 can thus be assigned as $\mathrm{C} 1(S)$ and $\mathrm{C} 4(R)$ based on $(\mathrm{D})$-serine. Overall the synthetic sequence to $(-)$-aplaminal 1 proceeded in 9 steps and in 17\% yield from commerical available $N$-Boc-(D)serine.

In summary, the total synthesis of the novel sea hare metabolite (-)-aplaminal $\mathbf{1}$ has been achieved exploiting vicinal tricarbonyl chemistry to access the imidazolidine core. Final ring closure employing $\mathrm{AlMe}_{3}$ in toluene proved particularly useful to generate the triazabicyclo [3.2.1]octane skeleton. Studies to both understand the conversion of (-)-7 to (+)-2 and extend 
this synthetic venture to a focused library of analoges for biological analysis will be reported in due course.

\section{Supplementary Material}

Refer to Web version on PubMed Central for supplementary material.

\section{Acknowledgments}

The authors dedicate this letter to Professor Henry Wasserman (Yale University), a friend, scholar and pioneer in the chemistry of tricarbonyl chemistry. Support was provided by the National Institute of Health (Institute of General Medical Sciences) through grant GM-29028 and the University of Pennsylvania. We thank Drs. G. Furst, J. Gu, R. Kohli and Dr. P. Carroll (University of Pennsylvania) for assistance in obtaining NMR spectra, high-resolution mass spectra, and X-ray analysis respectively. Finally, the authors would like to thank Professor Jon Rainier (University of Utah) for his insightful suggestions.

\section{References}

1. Kuroda T, Kigoshi H. Org. Lett 2008;10:489. [PubMed: 18184001]

2. Tietze LF, Bratz M. Org. Synth 1993;71:214.

3. Wasserman H, Parr J. Acc. Chem. Res 2004;37:687. [PubMed: 15379584]

4. Luly JL, Dellaria JF, Plattner JJ, Soderquist JL, Yi N. J. Org. Chem 1987;52:1587.

5. Catalano JG, Deaton DN, Furfine ES, Hassell AM, McFadyen RB, Miller AB, Miller LR, Shewchuk LM, Willard DH, Wright LL. Bioorg. Med. Chem. Lett 2004;14:275. [PubMed: 14684342]

6. Kayser KJ, Glenn MP, Sebti SM, Cheng JQ, Hamilton AD. Bioorg. Med. Chem. Lett 2007;17:2068. [PubMed: 17276059]

7. Hu F, Zhang Y, Yao Z. Tetrahedron Lett 2007;48:3511.

8. Taber DF, Deker PB. J. Org. Chem 1988;53:2968. 


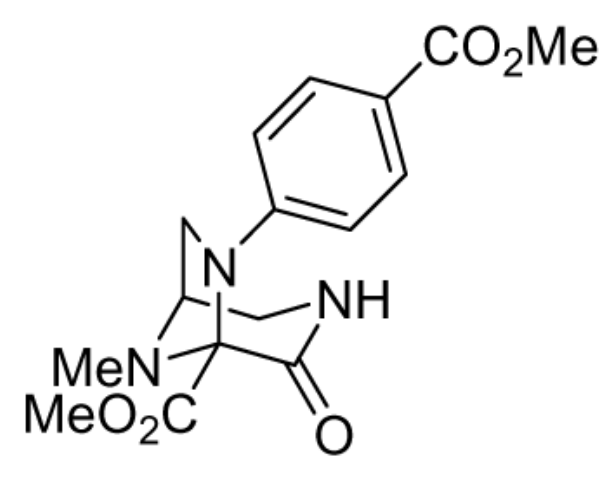

(-)-Aplaminal (1)

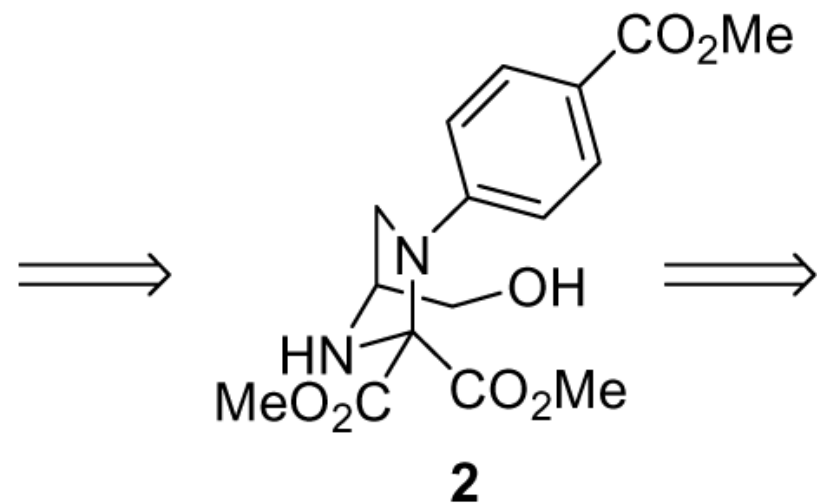<smiles>COC(=O)C(=O)C(=O)OC</smiles><smiles>COC(=O)[C@H](COCc1ccccc1)NC(=O)c1ccccc1</smiles>

$(-)-5$

Scheme 1. 
<smiles>COC(=O)[C@H](COc1ccccc1)NC(=O)c1ccccc1</smiles>

$(-)-5$ i. DIBAL-H

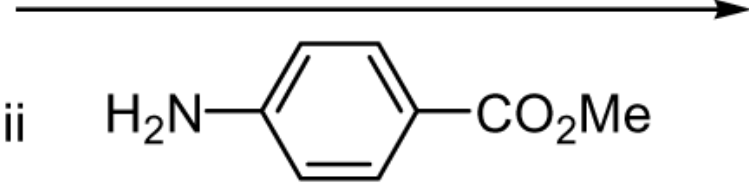

$\mathrm{NaCNBH}_{3}$

(72\%)<smiles>COC(=O)C(=O)OC(=O)C(=O)OC</smiles>

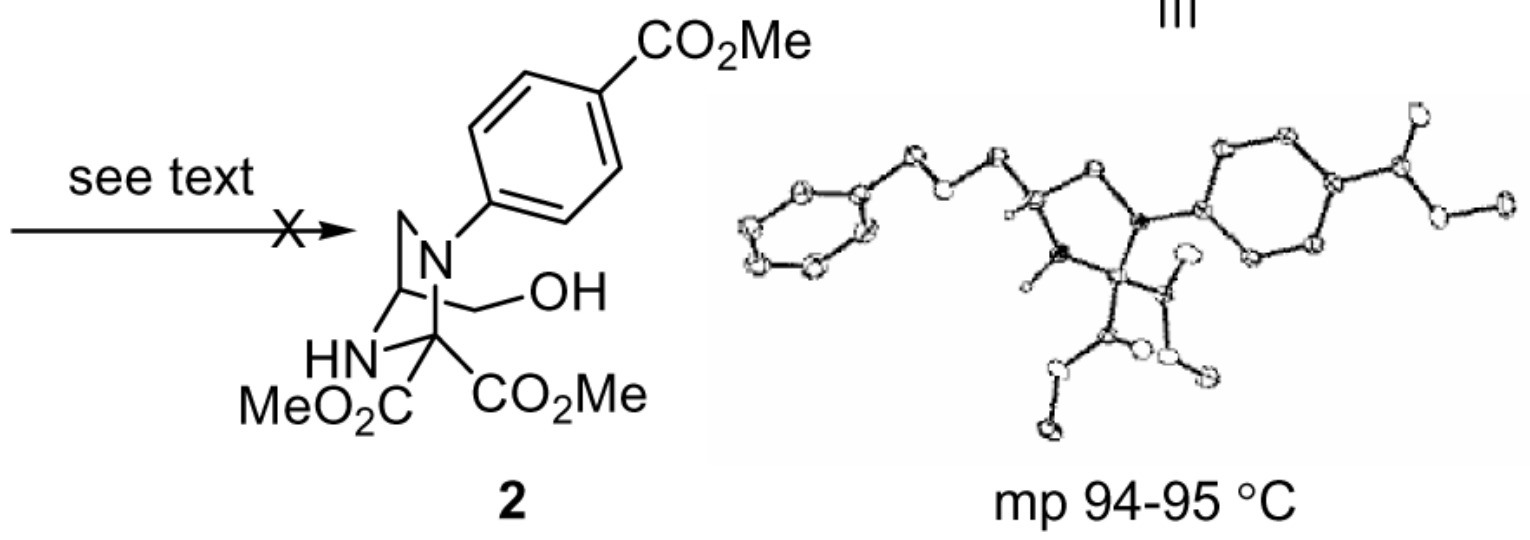

Scheme 2. 


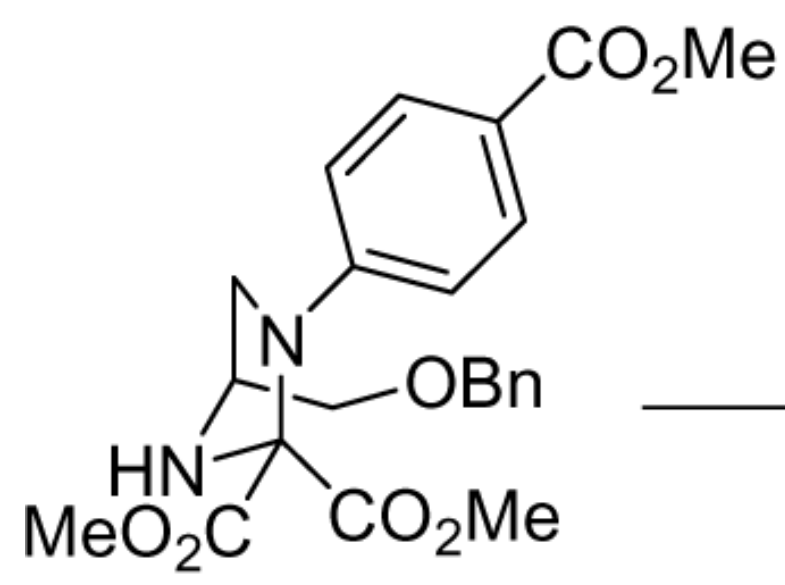

$\mathrm{H}_{2}$

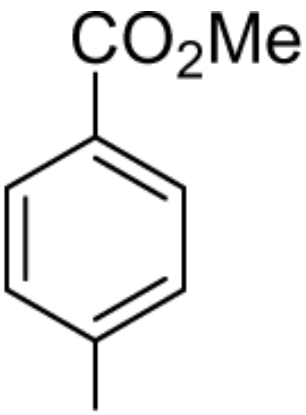

$(+)-6$

(75\%)
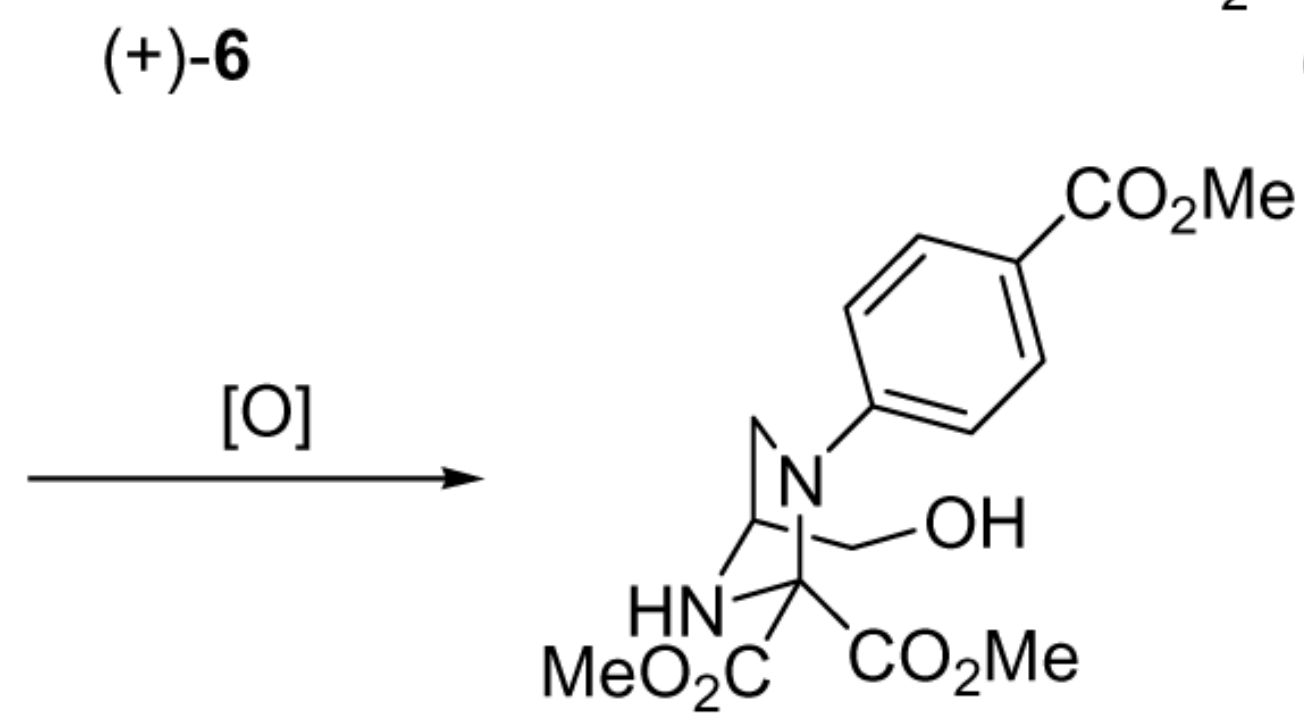

(+)-2

Scheme 3. 


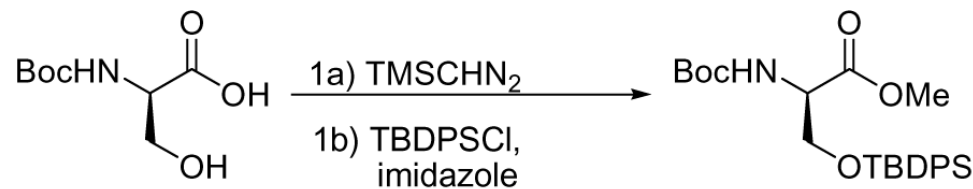
$(-)-8$
(95\%)
$(-)-9$<smiles>COC(=O)C(=O)C(=O)OC</smiles>

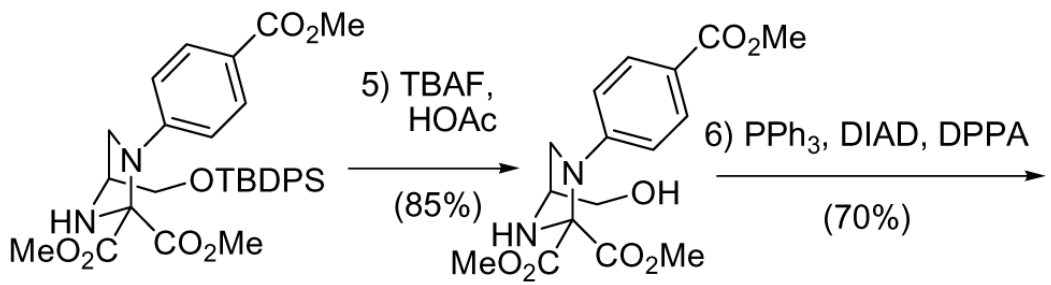

$(+)-11$

$(+)-2$

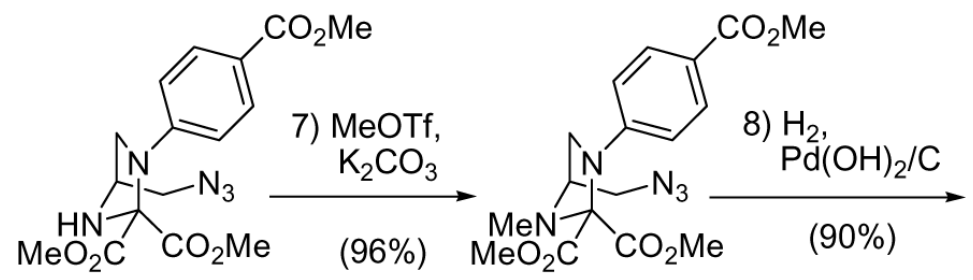

$(+)-12$

$(+)-13$

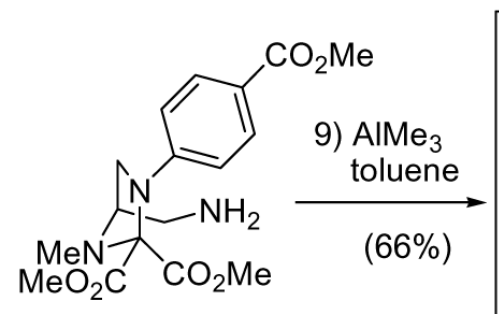

$(+)-14$

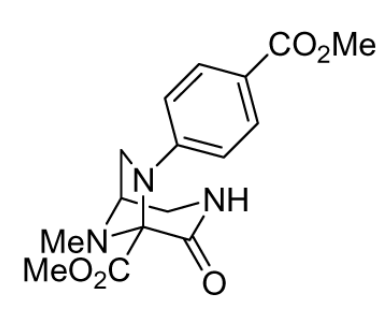

(-)-Aplaminal (1)

Scheme 4. 